\section{Forecasting in airforce supply chains}

Forecasting in airforce supply chains

\author{
Matthew Downing
}

Boeing Defence UK Limited, Gosport, UK

Maxwell Chipulu and Udechukwu Ojiako

School of Management, University of Southampton, Southampton, UK, and

Dinos Kaparis

The Management School, Lancaster University, Lancaster, UK

\section{Abstract}

Purpose - The UK Chinook helicopter is a utility and attack helicopter being operated by the Royal Air Force (RAF). Its versatile nature is of enormous importance to the strategic capability of the RAF's operations. The purpose of this paper is to utilise systems-based forecasting to conduct an evaluation of inventory and forecasting systems being used to support its maintenance programme.

Design/methodology/approach - A case study is conducted. Data are collected from existing monthly Component Repair (CRP) data and performance evaluation of software. For propriety reasons, all data have been sanitised.

Findings - Analysis of the current inventory and forecasting system suggests a possible lack of forecasting precision. Current non-specific formulation of forecasting techniques implied several of the cost driver's demands were being miscalculated. This lack of precision is possibly a result of the smoothing value of 0.01 being too low, especially as the results of statistical modelling suggest that current parameter values of 0.01 might be too low.

Originality/value - The paper reports on work conducted jointly between Boeing and the University of Southampton that sought to create an intermittent demand forecasting model.

Keywords Helicopters, Maintenance programmes, Inventory, Supply chain management, Forecasting, United Kingdom

Paper type Case study

\section{Introduction}

The Royal Air Force (RAF) is the military air force of the UK. It was created in 1918 and is the world's oldest independent air force. The RAF currently operates over 1,000 aircraft (Jane's Analysts, 2009). One of the aircraft operated by the RAF is the Chinook CH-MK/MK2a tandem rotor helicopter. This aircraft, which first saw service in 1962 (in the US Army), was adopted by the RAF as its flagship utility aircraft in 1980. The Chinook remains one of the force's most versatile aircraft operated by the RAF which operates the largest fleet of Chinook helicopters (apart from the US Army). Due to its versatility, the Chinook can serve in various roles including transport, casualty evacuation, and rescue. It can also serve comfortably in various weather conditions or at night. All these reasons make it a particularly important aircraft to the RAF [Ministry of Defence $(\mathrm{MoD}), 2004]$.

\section{Background}

In order to enhance the RAF's capabilities, the UK MoD (MoD, 2004) in 2004 made a decision to transfer all home-based maintenance of the Chinook helicopter to private organisations. By awarding the maintenance contract to private organisations, the UK MoD hoped to free up RAF personnel for frontline aircraft maintenance (which would have been not only more expensive, but also would have had insurance implications). 
IJLM

22,1

128

At the same time, the $\mathrm{MoD}$ anticipated financial and efficiency savings emerging from such a programme. For example, Withington (2008) points out that outsourcing the maintenance programme to a private organisation was expected to deliver to the RAF substantial financial savings. The project is also to ensure that maintenance duration of the Chinook helicopters is reduced.

The maintenance contract was awarded to Boeing UK. Direct maintenance is through Boeing's UK Through Life Customer Support team (UKTLCS). Boeing's main supply chain objective is to maintain aircraft availability for the RAF. This involves ensuring that spare components to support the UK Chinook maintenance programme are delivered at the right time to the right location. Support for the UKTLCS's forecasting endeavour is provided by an integrated inventory management system, the Service Planning and Optimisation System (SPO).

The SPO was created by MCA solutions. It is used by the UKTLCS to manage its maintenance programme. The software provides adapted modelling capabilities, which has proved useful to major fluctuations in the Chinook's spare component demand. Although this has been the case, management at UKTLCS commissioned a study to examine possible enhancements to the SPO system, with a view to improving the level of precision delivered by the system (considering peculiarities of the nature of the project).

The major desire of the UKTLCS team was to reconfigure SPO to meet specific requirements identified as the following:

- allowing the choice of the number of periods to forecast for;

- based on the amount of data needed for the seasonality modelling, to prepare forecasts for any time series size above 12 months;

- optimisation or fixed parameters readily available;

- an ability to choose the number of hold out periods to assess the model against;

- allow assessment of forecast performance against numerous statistics of fit;

- produce forecasts for more than one time series; and

- analyse autocorrelation, graphical output, and relationships between flying hours and demand.

Based on this, the objectives of this study will be to:

(1) conduct a review of existing inventory management and forecasting tools; and

(2) evaluate the performance of these tools against data emerging from the SPO toolset.

To achieve these objectives, real-life data will be utilised. For expediency of the research (due to the large number of Chinook spare components) the study will focus on components with high value cost drivers. The study is seminal due to the nature of demand-based forecasting which remains a critical element in not only decision making (Clark and Grant-Muller, 2005; Beamon and Kotleba, 2006; Graman and Sanders, 2009) and risk management associated with over-stocking of components (Markland, 1970; Ghobbar and Friend, 2003; Regattieri et al., 2005), but also general concerns about the impact of forecasting on operational efficiencies (Rafuse, 1995). In addition, although research that focuses on forecasting for military equipment has been extensive (see Denicoff et al., 1960; White, 1993; Regattieri et al., 2005; 
Syntetos, 2007; Tysseland, 2009), research that actually focuses on spare part demand forecasting for rotary winged military aircraft (helicopters), remains limited. Research has shown that efforts to manage the supply chain are likely to be unsuccessful if demand forecast is inaccurate (see Sayed et al., 2009). It, however, remains difficult to conduct such forecasts accurately because of limited data not only in non-zero but spare component demand (Huang, 2009), especially of those in the military arena (Michaels, 1999; Johnsen et al., 2009; Tysseland, 2009). Put into perspective, in the past few years alone, well-known demand models (Ghobbar and Friend, 2003; Willemain et al., 2004; Dolgui and Pashkevich, 2008; Syntetos et al., 2009a; Teunter and Sani, 2009) have attracted numerous citations, leading to a conclusion that demand modelling remains at the centre of forecasting scholarship. This study is driven by recognition that many of the more advanced forecasting techniques, such as higher order autoregressive integrated moving average (ARIMA) models appear unable to process the slow moving nature of the demand (Syntetos et al., 2009b; Wallstrom, 2009). For this reason, they end up creating large errors in forecast projections (Pack, 1990). On the other hand, simple averaging methods do not capture the true essence of any pattern showing a need for unique dedicated forecasting techniques based on the type of demand (De Gooijer and Hyndman, 2006).

\section{The Chinook maintenance programme}

The Chinook helicopter is a complex aircraft made up of over 13,000 component parts. With so many parts, for the expediency of the research exercise, and working with management at UKTLCS, a decision was made to scale back the project to a level where data would be more easily manageable. For this reason, based on earlier work by Karr (1958), Denicoff et al. (1960), and Dekker et al. (1998), the research project focused on key spare components. Selection of key components was made based on advice by UKTLCS engineers. Selection was based on cost and component criticality. Based on this, a selection of the 92 most critical components of the helicopter was made. This study focuses on these key spare components. Identification of each spare component is achieved by cross referencing against unique reference numbers. In addition, each component is cross referenced against replacement characteristics.

The Chinook maintenance programme is managed from four different sites located across the UK (one in Perth, Scotland; two sites in Hampshire, England; and one in Wales). The entire maintenance operations are managed using an MCA Corp developed system called SPO.

\section{The SPO inventory management and forecasting toolset}

SPO is a proprietary service-focused inventory planning and forecasting toolset used by UKTLCS to manage the supply chain on its Chinook maintenance programme. SPO functionality allows for the following:

- managers to forecast future demand based on historical order and stocking trends and restrictions placed by individually tailored service level agreements; and

- the software can be easily configured and scaled to meet specific supply chain conditions (e.g. cash flows, location of spare components, contract conditions).
Forecasting in airforce supply chains

129 
IJLM

22,1

130

As it stands, UKTLCS uses a generic method of forecasting which based on:

- the location of spare components across four sites in the UK; and

- flying hours following the use of Mean Time between Failure method in establishing the relationship between flying hours and the amount of spares required.

Therefore, in theory an increase in flying hours will increase the demand for spares. In cases where management felt that generic method of spare component forecasting were not suitable, the MCA smoothing method which is a variant of the single exponential smoothing (SES) method that is tailored towards intermittent demand time series was employed (Erkern, 1981; Billah et al., 2006; Gardner, 2006). The authors note that some of the very slow moving items and consumables use a combination of the time series forecast and the replacement rate of the product to create a forecast. However, the replacement rate is not information readily available; therefore, for the purpose of this essay, all analysis will be conducted without referring to replacement rates.

This paper is divided into five major sections. They comprise of an introduction which provides an overview of the Chinook maintenance programme, and the SPO toolset. The second section of the paper presents a review of the related literature on forecasting models. While the third section presents the research methodology, in the penultimate section of the paper, the authors discuss the findings of the research. The paper concludes in the fifth section.

\section{Review of literature}

Forecasting models

Erratic and intermittent (sometimes referred to as lumpy) demand for spare components is often caused by a small number of customers or small fleet size where the demand pattern is not always clear (Johnston and Boylan, 1996; Willemain et al., 2004). This demand type is often exhibited in environmentally sensitive service environments such as aircraft (Ghobbar and Friend, 2003), and military spare component demands (Markland, 1970; White, 1993; Regattieri et al., 2005; Syntetos, 2007). Based on this, the relative importance of choosing an appropriate forecasting technique to support decision making cannot be over-emphasised.

One of the most popular means of forecasting demand is exponential smoothing (Erkern, 1981; Billah et al., 2006; Gardner, 2006). Originating from earlier work conducted by Brown (1959), the methodology has remained a critical basis of modelling where patterns are not noticeable. However, on occasions when trends are noticeable, Holt's (1957) linear exponential smoothing (LES) provides a natural progression using two parameters, one for trend and one for smoothing the time series. In practice, smoothing methods continue to dominate supply chain management scholarship by being embedded in a majority of, if not all, relevant inventory control packages (Gardner, 2006; Syntetos et al., 2009b). Often the choice of smoothing method has been the hardest part in previous studies. Pagels' (1969) classification allowed an easy framework for discussing these matters. However, with so many series with zero demand months the use of a multiplicative method is difficult to implement.

One of the most commonly employed smoothing techniques is the SES, which is popular due to its low computational effort and high dexterity. The method takes the previous period's forecast in conjunction with the new entered demand $Y_{i}$ and uses an adjustment parameter $\alpha$ to lower the forecast error, $Y_{t-1}-F_{t-1}$, of the last period. It 
self-adjusts based on each new period that is entered into the forecast

$$
\begin{aligned}
& F_{t}+1=\alpha Y_{t}+(1-\alpha) F_{t} \\
& 0 \leqslant \alpha \leqslant 1
\end{aligned}
$$

Most of the time the forecast will look as though it is trailing the actual values as the nature of the equation means the adjustment of the error is only made one period ahead. It also means that the dependence of previous values $Y_{t}, Y_{t-1}, Y_{t-2}, \ldots$ falls away in an exponential way and the weighting may emphasise the most recent nature of the data. SES works best in data which exhibit no pattern, seasonal effect, or upward/downward trend. The forecast horizon of SES is assumed to be "flat", such that:

$$
F_{t+h}=F_{t+1} \quad h=2,3, \ldots \ldots
$$

A typical smoothing constant between 0.1 and 0.3 is suitable for SES when forecasts are conducted on a monthly basis (Silver et al., 1998). When a smaller weight is chosen, the initial forecasts play more of an active role than with a large $\alpha$. When $\alpha=1$, the forecast becomes the same as NF1, the naïve forecast:

$$
\begin{aligned}
& F_{t+1}=\alpha Y_{t}+(1-\alpha) F_{t} \\
& \text { Let } \alpha=1, \\
& F_{t+1}=\left(1 \times Y_{t}\right)+(1-1) F_{t} \\
& F_{t+1}=Y_{t}
\end{aligned}
$$

Typically optimisation of the smoothing weights via mean squared error (MSE) of mean absolute percentage error (MAPE) provides the best forecasting based on the performance metric, rather than choosing a weight.

SES has been proven to work well when inter-demand periods are less than 1.25 , although it does have the problem of overestimation when the forecast update happens straight after the demand.

An extension of SES is Holt's LES, which takes into account a possible (local) linear trend. There are two smoothing constants $\alpha$ and $\beta$, where $0<\alpha, \beta<1$. In addition to $\alpha$, the smoothing constant, a trend value $\beta$ is introduced to capture any patterns in the data. See Equation (4) for the LES equations can be written in the following form:

$$
\begin{aligned}
& L_{t}=\alpha Y_{t}+(1-\alpha)\left(L_{t-1}+b_{t-1}\right) \\
& b_{t}=\beta\left(L_{t}-L_{t-1}\right)+(1-\beta) b_{t-1} \\
& F_{t+m}=L_{t}+b_{t} m
\end{aligned}
$$

where $L_{t}$ denotes an estimate of the level of the series at time $t$ which updates directly from last periods trend, $b_{t}$ denotes an estimate of the slope of the series at time $t$ and updates the trend accordingly (Makridakis et al., 1998). The combination of the two creates the next forecast value.

This further extension of exponential smoothing introduces the possible seasonal trend in the time series. The first of the two methods is Holt Winters' (HW) multiplicative method for seasonal time series. Using a newly introduced parameter $\gamma$, a trend based on the most recent season is created. The equations of HW multiplicative 
IJLM

22,1

132

are therefore as follows:

$$
\begin{aligned}
& L_{t}=\alpha \frac{Y_{t}}{S_{t-s}}+(1-\alpha)\left(L_{t-1}+b_{t-1}\right) \\
& b_{t}=\beta\left(L_{t}-L_{t-1}\right)+(1-\beta) b_{t-1} \\
& S_{t}=\gamma \frac{Y_{t}}{L_{t}}+(1-\gamma) S_{t-s} \\
& F_{t+m}=\left(L_{t}+b_{t} m\right) S_{t-s+m}
\end{aligned}
$$

where $S_{t}$ is the newly developed seasonal factor of the equation. The equation uses one complete cycle to initialise the forecast such that:

$$
\begin{aligned}
L_{s} & =\frac{1}{s}\left(Y_{1}+Y_{2}+\ldots Y_{s}\right) \\
b_{s} & =\frac{1}{k}\left(\frac{Y_{s+1}+Y_{1}}{s}+\frac{Y_{s+2}+Y_{2}}{s}+\ldots+\frac{Y_{s+k}+Y_{k}}{s}\right) \\
S_{k} & =\frac{Y_{k}}{L_{s}} \quad k=1,2 \ldots, s
\end{aligned}
$$

The seasonal component of HW method may also be treated additively, although this is less common (Makridakis et al., 1998). The equations for the HW additive method are as follows:

$$
\begin{aligned}
& L_{t}=\alpha\left(Y_{t}-S_{t-s}\right)+(1-\alpha)\left(L_{t-1}+b_{t-1}\right) \\
& b_{t}=\beta\left(L_{t}-L_{t-1}\right)+(1-\beta) b_{t-1} \\
& S_{t}=\gamma\left(Y_{t}-L_{t}\right)+(1-\gamma) S_{t-s} \\
& F_{t+m}=L_{t}+b_{t} m+S_{t-s+m}
\end{aligned}
$$

The only differences in the other equations are that the seasonal indices are now added and subtracted instead of taking products and ratios (Makridakis et al., 1998). The way in which $L_{t}$ and $b_{t}$ are initialised is exactly the same as the multiplicative method. To initialise $S_{1}$ the following formula is used (See Equation 8):

$$
S_{1}=Y_{k}-L_{s} \quad k=1,2 \ldots, s
$$

Another commonly used exponential smoothing methodology is Croston's (1972) method, which put forward a proposal that the essence of forecasting relates to capturing the compound nature of the underlying demand structure. Fundamentally, Croston's (1972) work is based on an assumption that demand sizes are independent and identically distributed; the implication being that forecasts would need to be adjusted when new demand occurs.

Let $z_{t}$ be the demand size, $p_{t}$ equal the demand interval, and $q$ is the number of periods since the last demand. The equations (See Equation (9) and Equation (10)) can be written in the following form[1]:

If $y_{t}=0$ then,

$$
\begin{aligned}
p_{t} & =p_{t-1} \\
z_{t} & =z_{t-1} \\
q & =q+1
\end{aligned}
$$


otherwise,

$$
\begin{aligned}
& p_{t}=p_{t-1}+\alpha\left(q-p_{t-1}\right) \\
& z_{t}=z_{t-1}+\alpha\left(y_{t}-z_{t-1}\right) \\
& q=1
\end{aligned}
$$

The size and interval combine to form, $\hat{y}_{t}=z_{t} / p_{t}$ to become equal to SES. Therefore if there is no period of zero demand then the results of SES would equal Croston's method. Croston's method has the ability to reduce the bias that SES has; therefore it is often preferred over SES in slow moving demand. It does still however keep an element of bias which Syntetos and Boylan $(2001,2005)$ tried to reduce with their approximation method. Although it is arguable that Croston's (1972) work remains seminal in forecasting scholarship (see Willemain et al., 1994; Snyder, 2002; Leven and Segerstedt, 2004; De Gooijer and Hyndman, 2006; Boylan and Syntetos, 2007; Teunter and Sani, 2009), scholars such as Willemain et al. (1994) and Teunter and Sani (2009) are beginning to question the accuracy of Croston's (1972) model. For example, it has also been suggested that the model is also "biased" and over estimates the demand. For example, Syntetos and Boylan $(2001,2005)$ had conducted substantial research around the extent of bias of the model because, if it is assumed that estimators of demand size $\left(Z_{t}\right)$ and demand interval $\left(p_{t}\right)$ are independent then:

$$
E\left(\frac{z_{t^{\prime}}}{p_{t^{\prime}}}\right)=E\left(z_{t^{\prime}}\right) E\left(\frac{1}{p_{t^{\prime}}}\right)
$$

But,

$$
E\left(\frac{1}{p_{t^{\prime}}}\right) \neq \frac{1}{E\left(p_{t^{\prime}}\right)}
$$

Syntetos and Boylan $(2001,2005)$ in recent years have created a revision of Croston's method to overcome the alleged biasness of the model which is named their approximation method (SBA). By using an unbiased estimator, the SBA method deflates Croston's method by a factor $(1-\beta / 2)$ where $\beta$ is the same used to update the SES estimate of the mean inter-arrival time for demand (Syntetos et al., 2009b). Many have approved the validity of this factor including Eaves and Kingsman (2004). Therefore the demand for a given period can be written as the following:

$$
\hat{y}_{t}=\left(1-\frac{\beta}{2}\right) \frac{Z_{t}}{P_{t}}
$$

Unlike Croston's method, when demand occurs, the smoothing constant does not become equal to that of SES, as the bias corrector is not affected. For this reason it is suggested that Croston's (1972) method is biased. His model, the Syntetos and Boylan (2001, 2005) approximation method (SBA), uses an unbiased estimator to overcome Croston's shortfall. Leven and Segerstedt (2004) also created an alternative version of Croston's method. Another commonly used exponential smoothing methodology is ARIMA. This modelling approach was developed by George Box and Gwilym Jenkins (1970) and is used in situations when patterns are not noticeable. Two questions arise when choosing which ARIMA model to use. First, the basic assumption of 
IJLM

22,1

134

independence in the series can easily have a heavy violation of the residuals (McKenzie, 1988; Pack, 1990; Ho and Xie, 1998). Second - and arguably - the most important factor is the length of the time series in which to use (Ho and Xie, 1998). ARIMA is often not recommended because of the presence of zero demands (Eaves and Kingsman, 2004). As a generalised rule of thumb ARIMA needs at least 30 observations (Ord et al., 2001) where trend patterns can be easily observed. It must be noted that in themselves, exponential smoothing methods have been shown to be special case ARIMA models (see Table I).

It is important to highlight that the two earlier means of forecasting demand are based on quantitative and statistical rigour. As in most cases, forecasting does have a heuristical element. This is called judgement forecasting. Judgement forecasting is often undertaken in hard to predict time series (Zinn, 1990; Bunn and Wright, 1992; Syntetos et al., 2009a). This process, although attracting the attention of scholars (Armstrong, 2001), is associated with risk due to an element of personal bias (Sniezek, 1989).

It is probably important to highlight that in addition to the forecasting approaches that have been discussed (exponential smoothing and Croston's methodology), there also exist less well-known forecasting techniques in areas such as Bayesian forecasting (Zellner, 1986). In addition, recent scholarship in recognition of the individual limitations associated with each of these models has sought to encapsulate positive aspects through methodology combination (Clements and Hendry, 1998; Armstrong, 2001).

The authors note that with forecasting methods $F_{1}, F_{2}, F_{3}, \ldots, F_{n}$, using a combination model with equal weights would be equated in the following form:

$$
\begin{aligned}
& C=w_{1} F_{1}+w_{2} F_{2}+w_{3} F_{3} \ldots \ldots \ldots w_{n} F_{n} \\
& \text { Where, } w_{1}+w_{2}+w_{3} \ldots \ldots \ldots w_{n}=1
\end{aligned}
$$

such an approach (see Palm and Zellner, 1992) is likely to lead to a reduction in the likelihood of forecasting bias.

\section{Ensuring the precision of forecast}

In this section the various ways in which a forecast's precision can be ensured are discussed. Much of forecasting is centred on the precision of the forecast rather than the forecast itself. Murphy (1993) described what makes a forecast "good" which adds to the goodness-of-fit ideology:

- Consistency - How the forecast corresponds to the expert's judgement.

- Quality - The performance of the forecast against the actual observation.

- Value - How the forecast aids the decision maker in his/her choice of decision to realise a benefit.

Table I.

Forecasting models and their ARIMA equivalents
Model

Simple exponential smoothing

Double (Brown) exponential smoothing

Holt's linear exponential smoothing

Damped-trend linear exponential smoothing

Seasonal exponential smoothing

Winters method - additive
ARIMA equivalent

$\operatorname{ARIMA}(0,1,1)$

$\operatorname{ARIMA}(0,2,2)$

$\operatorname{ARIMA}(0,2,2)$

$\operatorname{ARIMA}(1,1,2)$

$\operatorname{ARIMA}(0,1, p+1)(0,1,0)_{p}$

$\operatorname{ARIMA}(0,1, p+1)(0,1,0)_{p}$ 
The aspect of "Quality" concerns itself with the theory of "fit". Thus a measure of quality is in fact one which exhibits the smallest possible error between the actual and the forecasted demand.

One of the simplest ways of assessing the precision of a forecast is to assess its error. This is simply the difference between the observed value of demand against projected values, thus represented mathematically as $e_{t}=Y_{t}-F_{t}$. This measure does not depend in any form on how the forecast was produced. The precision of forecast is particularly important due to the role that forecasting has in decision making and strategic planning (Clark and Grant-Muller, 2005; Graman and Sanders, 2009). A mathematical representation of forecasting precision that takes into account overall overestimation and underestimation is the mean error (ME). This simply summates the values of the error $e$ and divides this by the number of observations within the time series, such that:

$$
M E=\frac{1}{n} \sum_{t=1}^{n} e_{t}
$$

This formula also allows for an identification of the excess/shortage in order to test the method's significance against the study's objectives. This can, however, only act as an average and not a performance of the forecast as negative errors have the ability to cancel positive errors, thus distorting the "true" performance of a forecasting technique. One way of diverting this problem (of cancellation) is to use method in which the sign of the error is eradicated. We could therefore take the square of the error term also known as the MSE which is represented in the following equation:

$$
M S E=\frac{1}{n} \sum_{t=1}^{n} e_{t}^{2}
$$

This will allow for a determination of a "true" error and the identification of "fit". These scale-dependent error calculations can and have been used extensively in performance measurement although the inter-relationship between series can be brought into question due to its heavy dependence on size. Other scale-dependent error measurements include using the absolute error $\left|e_{t}\right|$ (MAE) or the squared error, $\left|e_{t}^{2}\right|$ (MASE). MAE, also known as the mean absolute deviation (MAD) is widely used, although Wallstrom (2009) suggests that MAD is not reliable as it favours forecasting methods that underestimate the demand. In general, scale-dependent measure can be useful to estimate model parameters; however, other methods such as the relative geometric root-mean-square errors (RGRMSE) are often used in intermittent demand modelling which eliminates the effect of outliers. These methods are highly complex when presenting the ideas and the reason behind the results to management.

A percentage of the error which disregards the size of the demand using such methods as the mean percentage error (MPE) or the MAPE which, in a more general term, follow the same equation is created in Equation (17):

$$
p e_{t}=\frac{e_{t}}{Y_{i}} \times 100
$$

One of the most common disadvantages of using a percentage error method is its infinite or undefined result occurring in zero demand data. An alternative version of the MAPE can be derived by using the sum of the error divided by the actual demand to create a way of comparing the performance of the forecasts.
Forecasting in airforce supply chains

135 
IJLM

22,1

136

An area that all the above methods do not account for is the inter-relationship between forecasting methods. One such statistic that takes into account the importance of large error is Theil's $U$ statistic (Theil, 1966), which allows a relative comparison of formal forecasting methods with the naïve approaches. This squares the errors (see Equation (18)) involved so that large errors are given much more weight than small errors (Makridakis et al., 1998)

$$
U=\sqrt{\frac{\sum_{t=1}^{n-1}\left(\frac{F_{t+1}-Y_{t+1}}{Y_{t}}\right)^{2}}{\sum_{t=1}^{n-1}\left(\frac{Y_{t+1}-Y_{t}}{Y_{t}}\right)^{2}}}
$$

The interpretation of the ranges of output from the statistic can be shown as follows:

$U=1$ : A naive forecasting method is as good as the method in question.

$U<1$ : The forecasting method being used is better than a naive forecast.

$U>1$ : The naive forecast outperforms the method in question.

The statistic offers a good basis for the interpretation of previously used forecasts and also allows a method of comparison with the same naïve method used as the base.

A comparative metric of percentage best $(P B)$ is also useful when interpreting the performance of models against each other. Syntetos and Boylan $(2001,2005)$ used a comparative study of $P B$ for four forecasting methods in lumpy demand. $P B$ shows how many times over the period a forecast technique performs better than the others. If $N$ is the test sample size and $M$ is the set of forecasting methods, the mathematical expression for $\mathrm{PB}$ for method $M$ is represented as

$$
P B_{m}=\left(\left(\sum_{t=1}^{N} B_{m}\right) / N\right) \times 100
$$

where $B_{m}=1$ if $\left|F_{m, t}-A_{t}\right|$ is the minimum of all $\left|F_{m, t}-A_{t}\right|$ for $j \in M$, else $B_{m}=0$.

In conclusion, it must be remembered that when drawing inferences about relationships between series scales, dependent statistics cannot be used. It must also be noted that often scale-dependent errors will, when summarised, be dominated by the larger values from certain forecasted items (Fildes and Makridakis, 1988). MSE serves as a good evaluation tool of the series itself but cannot be used to compare inter series; therefore the use of the alternative MAPE could be used across data patterns and ME to show the average error across the whole time series.

\section{Methodology}

The research focused on the operational efficiency of an organisation. The objective of the research has been to provide a critique of different forecasting techniques. The setting has been within Boeing's UKTLCS programme which maintains aircraft availability for the RAF. The challenge faced by the programme has been consideration of the volatile demand faced in military settings. Noting the extreme demand for customer focus in such a setting, a phenomenological research approach was adopted. This approach was adopted in order to ensure that contextual and rich understandings of events were reconciled with observations (Seymour, 2001). 
Case studies represent contextualised and historical accounts of phenomenon (Leonard-Barton, 1990) that have continued to gain popularity within the area of operations management (Voss et al., 2002), due not only to its ability to reconcile contextual boundaries that are blurred (Yin, 2003), but also by its ability to support the development of creative practitioner insight. There are various approaches that can be used to collect data during case studies which according to Voss et al. (2002), may include the review of relevant operational data and documentation.

This study involved one case study. The limitation of this approach is that observations and conclusions from the study may be limited in terms of its generalisation. Scholars such as Leonard-Barton (1990), also highlight the potential for exaggerating data which is obtained from a single source. In this study, data were collected in various stages. The first stage involved a request being made to the management of Boeing for the placement of a researcher from the University of Southampton, School of Management to conduct a study within Boeing. Once access was granted (leading to an initial four-month long placement), the second stage of data gathering commenced with the determination of critical components and their cost drivers. These data were obtained from monthly Component Repair (CRP) data provided by the UKTLCS team. The demand data were readily available in an Excel spreadsheet for data manipulation. This involved combining data on spare component demand with cost drivers. For the data sets that demonstrated negative values, we allocated a "zero" (0) to their value. Visual Basic for Applications (VBA) macro modelling (Roman et al., 2002), was used to generate historical data, where this information was missing.

\section{Discussion of results (evaluation of SPO)}

The next stage of the research was to conduct an evaluation of the current SPO configuration. The current system is used to support inventory and forecasting management across the Chinook maintenance programme. We used VBA to measure the precision of SPO. This was achieved by measuring it against real-life results. Table II shows existing performance of results (of SPO) against other randomly selected items (note that item 88 is highlighted as it serves as a typical example of a component to be examined for demand).

\begin{tabular}{|c|c|c|c|c|c|c|c|c|c|c|c|c|}
\hline Item & OBS & Demand & $\begin{array}{l}\text { Forecast } \\
\text { demand }\end{array}$ & $\begin{array}{l}\text { Total } \\
\text { error }\end{array}$ & $\begin{array}{c}\text { PCT error } \\
(\%)\end{array}$ & ME & MSE & MAE & $\begin{array}{c}\mathrm{MPE} \\
(\%)\end{array}$ & $\begin{array}{c}\text { MAPE } \\
(\%)\end{array}$ & USTAT & \\
\hline 10 & 6 & 6 & 5.76 & 0.24 & 4.06 & 0.04 & 0.00 & 0.04 & 4.06 & 4.06 & - & \\
\hline 12 & 6 & 28 & 24.47 & 3.53 & 12.61 & 0.59 & 4.97 & 1.68 & -2.84 & 33.48 & 0.42 & \\
\hline 32 & 13 & 61 & 66.51 & -5.51 & -9.03 & -0.42 & 17.52 & 3.44 & -109.52 & 138.49 & 0.76 & \\
\hline 58 & 13 & 97 & 137.06 & -40.06 & -41.30 & -3.08 & 31.51 & 4.47 & -108.65 & 118.84 & 1.27 & \\
\hline 65 & 6 & 33 & 26.83 & 6.17 & 18.69 & 1.03 & 6.42 & 2.03 & 2.70 & 35.99 & 0.65 & \\
\hline 66 & 13 & 6 & 26.72 & -20.72 & -345.28 & -1.59 & 4.72 & 1.88 & - & - & 1.61 & \\
\hline 67 & 13 & 133 & 129.24 & 3.76 & 2.83 & 0.29 & 59.73 & 7.01 & -108.22 & 147.14 & 0.90 & \\
\hline 68 & 6 & 0 & 6.50 & -6.50 & & -1.08 & 1.17 & 1.08 & - & - & - & \\
\hline \multirow{2}{*}{\multicolumn{13}{|c|}{ 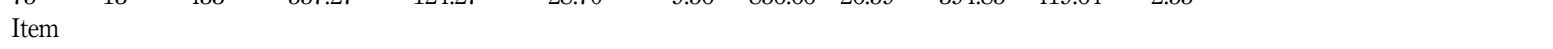 }} \\
\hline & & & & & & & & & & & & \\
\hline 88 & 6 & 12 & 73.75 & -61.75 & -514.58 & -10.29 & 125.92 & 10.29 & - & - & 2.05 & \\
\hline 89 & 6 & 111 & 112.56 & -1.56 & -1.40 & -0.26 & 201.58 & 12.80 & -129.97 & 163.35 & 1.49 & Table II. \\
\hline 90 & 13 & 458 & 874.27 & -416.27 & -90.89 & -32.02 & 1794.86 & 36.70 & -262.24 & 267.43 & 1.62 & Performance (of SPO) for \\
\hline 91 & 6 & 57 & 95.85 & -38.85 & -68.15 & -6.47 & 73.17 & 7.13 & - & - & 0.11 & randomly selected \\
\hline 92 & 13 & 578 & 601.61 & -23.61 & -4.08 & -1.82 & 909.92 & 23.05 & -132.73 & 166.72 & 0.90 & Chinook items \\
\hline
\end{tabular}

Forecasting in airforce supply chains

137 
IJLM

22,1

138
It can be observed from Table II that there is a substantial level of conflict. We note for example that $U$ forecast performance appeared to indicate attractive outcomes, especially with majority appearing to reside within a threshold of 1.00 . Overall, an example of such intermittent demand is shown by component number 88, which demonstrated the appearance of extreme demand volatility compared to either component number 32, 75, or 92 (see Table III). The authors are of the opinion that it may be that only a few forecasting techniques may be able to address time series of this, perhaps standing as a reason why such a demand pattern was not suitably addressed by MCA smoothing. In this case, it will appear that demand data forecast were overall poor, suggesting an inability of the software to adequately deal with dynamic time series patterns. It was noted that 157 individual units are ordered after numerous months of practically no demand. This is followed again by no record of demand for this component. It is possible however to infer that an understanding of poor precision in the forecast could be related to time series performances of some of the spare components.

We note that with an interval of demand greater than 1.25, performance of the worst performing spare components (Table IV) appeared similar to each other. It must be noted that 1.25 is a suggested cut off point when using certain intermittent demand models (see Johnston and Boylan, 1996). These components also exhibited large portions of no demand, with at least one period of high demand in the time series. However, the demand size does not seem to have a bearing on the results, with many having low overall mean values.

Overall, the outcome shows that none of the individual worst performing spare components demonstrated a trend that was fundamentally different from other spare components in this category. We feel that this outcome suggests that further exploration of the possible impact of outliers could be an avenue for further research. The method adopted can have an effect for which values are captured. If we were to use the technique of six standard deviations from the mean, the anomalies of the worst performing parts would not be taken from the data. Therefore the use of a well-known technique called windsorisation (see Tukey, 1962) could help proceedings. This takes the anomaly and smoothes it to the $n$th percentile in order to keep its significance in the data but stop its effect on the forecasts.

Further exploration of SPO was undertaken by conducting a comparison of $\alpha$ values which were created from VBA modelling (Roman et al., 2002). Based on earlier work by Markland (1970), we used simple exponential smoothing, to compare the $\alpha$ values. The results suggested that with an MSE (in and out), value of 69 and 56, respectively, against 23 and 36 for parameter values of 0.1 and 0.01 , parameter values of 0.1 provided a more precise forecast than those of 0.01 . The reasoning behind this change by UKTLCS management was to smooth the fluctuation in the forecasting value and in return lower the effect on the spiking target stock level (TSL). This parameter value however goes against all literature in the formulation of any inventory or intermittent demand models. It is also suggested by MCA solutions to use a value close to 0.1 , although anything within the region 0.1-0.2 is suggested. In theory, the lower the parameter value, the more likely the estimation will become a mean-based modelling process and older demand values will have a larger bearing on any future forecast. As already discussed, many of the demand patterns have changed massively in recent months/years; therefore the use of the low parameter value could be having a detrimental effect on forecasted estimations.

For the forecasting practitioner, observations from the study suggest that MCA smoothing values of 0.01 which are being used by UKTLCS management are too low 


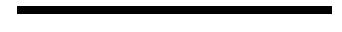

Table III. component 32,75 , 88 , and 92 


\begin{tabular}{|c|c|c|c|c|c|c|c|c|}
\hline $\begin{array}{l}\text { IJLM } \\
22,1\end{array}$ & Component & Location & Mean & High & $\begin{array}{l}\text { Standard } \\
\text { deviation }\end{array}$ & $\begin{array}{c}\text { Zero } \\
\text { frequency }\end{array}$ & Skewness & $\begin{array}{l}\text { Demand } \\
\text { interval }\end{array}$ \\
\hline \multirow{5}{*}{140} & 13 & Site A & 0.45 & 3 & 0.83 & 21 & 1.80 & 3.63 \\
\hline & 29 & Site B & 0.72 & 3 & 1.03 & 17 & 1.23 & 2.42 \\
\hline & 45 & Site B & 1.07 & 7 & 1.60 & 14 & 2.29 & 1.93 \\
\hline & 54 & Site A & 3.76 & 16 & 3.99 & 7 & 1.33 & 1.32 \\
\hline & 57 & Site B & 1.79 & 11 & 2.30 & 10 & 2.47 & 1.53 \\
\hline \multirow{4}{*}{$\begin{array}{l}\text { Table IV. } \\
\text { Spare components, worst } \\
\text { performing }\end{array}$} & 62 & Site A & 6.93 & 22 & 5.22 & 2 & 0.91 & 1.07 \\
\hline & 63 & Site B & 1.14 & 4 & 1.13 & 10 & 0.84 & 1.53 \\
\hline & 66 & Site A & 0.45 & 2 & 0.69 & 19 & 1.27 & 2.90 \\
\hline & 88 & Site C & 11.41 & 157 & 29.70 & 17 & 4.52 & 2.42 \\
\hline
\end{tabular}

and may be directly leading to a loss of precision in forecasting. It may therefore appear that although a low parameter of 0.01 is appropriate when demand is constant and stable, the reality is that military spare component demand is lumpy, and therefore not suitable for such low values. A conclusion that can be drawn from this is that an increase in the parameters value may allow for an increase in precision and in turn reduce the holding cost for UKTLCS.

\section{Conclusions}

The study focused on the maintenance of the RAF's fleet of Chinook CH-MK/MK2a tandem rotor helicopters by Boeing UK's UKTLCS team. The UKTLCS team has two primary objectives. The first is to deliver financial savings to the $\mathrm{UK} \mathrm{MoD}$, the second to complete the maintenance of each helicopter at a much reduced duration from existing timescales. As a result of these requirements and the complexity of the aircraft, a major element of the maintenance programme has been has focused on approaches that may be adopted to enhance forecasting precision. Of particular interest is in the use by the UKTLCS team of SPO, a proprietary service-focused inventory planning and forecasting toolset. In light of this, the primary objective of the study was to conduct a review of existing inventory management and forecasting tools, and evaluate the performance of these tools against data emerging from the SPO toolset. In order to achieve these objectives, the study was undertaken in the form of a review of existing forecasting techniques. The study also utilised real-life data obtained from existing monthly CRP data to conduct a performance evaluation of the SPO software. To undertake this task, VBA was employed. The uniqueness of the study was resided in its application to military settings which are generally characterised by erratic and intermittent demand for spare components.

The study found that the spare components mainly demonstrated similar trends; based on this, we employed modelling to compare $\alpha$ values. The outcome of the study appears to indicate that, because of their ability to smooth forecasting fluctuations, parameter values of 0.1 , provided a more precise forecast than those of 0.01 .

The overall conclusion from this study is that the incorporation into forecasting tools of enhanced dynamic functionalities will greatly enhance forecasting precision of cost drivers by Boeing's UKTLCS team. Indeed our findings are not necessarily out of line with existing thinking on military inventory forecasting. In a report by the United States Government Accountability Office (GAO, 2009), inaccurate demand forecasting was seen to be one of the reasons why military inventory estimates often 
failed to align with emerging requirements. To help address this imbalance, based on our findings, we put forward two key recommendations. The first recommendation involves the establishment of component metrics that can be easily updated and tracked. This is because without such flexibility, it is highly unlikely demand trends (and costs) will reflect current trends. The reality is that if this does not happen, forecasting models are likely to be based on inaccurate data. The second key recommendation may be to revisit current practice of basing forecast on monthly CRP data. It may be prudent to examine the possibility of reduce the forecast period for CRP data to two weeks in order to take into consideration resulting changes to demands driven by dynamic operational requirements of the RAF.

Overall, the authors are of the opinion that this research has highlighted the need for further exploration of higher order modelling and alternative modelling methodologies. The first in series of such future work may involve further testing of forecasting accuracy of SPO on other military aircraft supply chains. In addition, the use of techniques such as Bayesian theorem forecasting, bootstrapping and neural networks has the ability to add value to the study. The use of ARIMA once the length of time increases will also give an interesting insight once patterns start emerging in the data. The authors are also of the opinion that there may be a need to explore the relationship between the forecasts and the TSL spikes occurrence and the use of replacement rates in the overall forecasts. Also, work into intervention analysis and intervention variables may add value where outliers and pattern changes were exhibited in the SPO forecast.

\section{Note}

1. Various methods of Croston's are used in study. This formulation however is the most common.

\section{References}

Armstrong, J. (2001), Combining Forecasts, Marketing Papers, University of Pennsylvania, Philadelphia.

Beamon, B. and Kotleba, S. (2006), "Inventory management support systems for emergency humanitarian relief operations in South Sudan", International Journal of Logistics Management, Vol. 17 No. 2, pp. 187-212.

Billah, B., King, M., Snyder, R. and Koehler, A. (2006), "Exponential smoothing model selection for forecasting”, International Journal of Forecasting, Vol. 22 No. 2, pp. 239-47.

Box, G. and Jenkins, G. (1970), Time Series Analysis: Forecasting and Control, Holden-Day, San Francisco, CA.

Boylan, J. and Syntetos, A. (2007), "The accuracy of a modified Croston procedure", International Journal of Production Economics, Vol. 107 No. 2, pp. 511-17.

Brown, R. (1959), Statistical Forecasting for Inventory Control, McGraw-Hill, New York, NY.

Bunn, D. and Wright, G. (1992), "Interaction of judgemental and statistical forecasting method: issues and analysis", Management Science, Vol. 37 No. 5, pp. 501-18.

Clark, A.D. and Grant-Muller, S.M. (2005), "Using nonparametric tests to evaluate traffic forecasting performance", Journal of Transportation and Statistics, Vol. 5 No. 1, pp. 47-56.

Clements, M.P. and Hendry, D.F. (1998), Forecasting Economic Time Series, Cambridge University Press, Cambridge.

Croston, J.D. (1972), "Forecasting and stock control for intermittent demands", Journal of the Operational Research Society, Vol. 23 No. 3, pp. 289-304.
Forecasting in airforce supply chains 
IJLM

22,1

142
De Gooijer, J. and Hyndman, R. (2006), "25 years of time series forecasting”, International Journal of Forecasting, Vol. 22 No. 3, pp. 443-73.

Dekker, R., Kleijn, M. and de Rooij, P. (1998), “A spare parts stocking policy based on equipment criticality”, International Journal of Production Economics, Vols 56-57, pp. 69-77.

Denicoff, M., Fennell, J. and Solomon, H. (1960), "Summary of a method for determining the military worth of spare parts", Naval Research Logistics Quarterly, Vol. 7 No. 3, pp. 221-34.

Dolgui, A. and Pashkevich, M. (2008), "On the performance of binomial and beta-binomial models of demand forecasting for multiple slow-moving inventory items", Computers and Operations Research, Vol. 35 No. 3, pp. 893-905.

Eaves, A.H.C. and Kingsman, B.G. (2004), "Forecasting for the ordering and stock-holding of spare parts", Journal of the Operational Research Society, Vol. 55, pp. 431-7.

Erkern, S. (1981), "Adaptive exponential smoothing revisited", Journal of the Operational Research Society, Vol. 32 No. 9, pp. 775-82.

Fildes, R. and Makridakis, S. (1988), "Forecasting and loss functions", International Journal of Forecasting, Vol. 4 No. 4, pp. 545-50.

GAO (2009), "Army needs to evaluate impact of recent actions to improve demand forecasts for spare parts”, www.gao.gov/new.items/d09199.pdf (accessed 23 September 2010).

Gardner, E. (2006), "Exponential smoothing: the state of the art - part II", International Journal of Forecasting, Vol. 22 No. 4, pp. 637-66.

Ghobbar, A. and Friend, C. (2003), "Evaluation of forecasting methods for intermittent parts demand in the field of aviation: a predictive model”, Computers and Operations Research, Vol. 30 No. 14, pp. 2097-114.

Graman, G. and Sanders, N. (2009), "Modelling the tradeoff between postponement capacity and forecast accuracy", Production Planning and Control, Vol. 20 No. 3, pp. 206-15.

Ho, S. and Xie, M. (1998), "The use of ARIMA models for reliability forecasting and analysis", Computers and Industrial Engineering, Vol. 35 Nos 1-2, pp. 213-16.

Holt, C.C. (1957), Forecasting Seasonals and Trends by Exponentially Weighted Moving Averages: Volume 52, Carnegie Institute of Technology, Pittsburgh, PA.

Huang, M. (2009), "Real options approach-based demand forecasting method for a range of products with highly volatile and correlated demand", European Journal of Operational Research, Vol. 198 No. 1, pp. 867-77.

Jane's Analysts (2009), Jane's World Armies, Coulsdon.

Johnsen, T., Howard, M. and Miemczyk, J. (2009), "UK defence change and the impact on supply relationships”, Supply Chain Management: An International Journal, Vol. 14 No. 4, pp. 270-9.

Johnston, F.R. and Boylan, J.E. (1996), "Forecasting for items with intermittent demand", The Journal of the Operational Research Society, Vol. 47 No. 1, pp. 113-21.

Karr, H. (1958), "A method of estimating spare-part essentiality", Naval Research Logistics Quarterly, Vol. 5 No. 1, pp. 29-42.

Leonard-Barton, D. (1990), "A dual methodology for case studies: synergistic use of a longitudinal single site with replicated multiple sites", Organisation Science, Vol. 1 No. 1, pp. 248-66.

Leven, E. and Segerstedt, A. (2004), "Inventory control with a modified Croston procedure and Erlang distribution”, International Journal of Production Economics, Vol. 90 No. 3, pp. 361-7.

McKenzie, E. (1988), “A note on using the integrated form of ARIMA forecasts”, International Journal of Forecasting, Vol. 4 No. 1, pp. 117-24. 
Makridakis, S., Wheelwright, S.C. and Hyndman, R.J. (1998), Forecasting: Methods and Applications, John Wiley \& Sons Inc, New York, NY.

Markland, R. (1970), “A comparative study of demand forecasting techniques for military helicopter spare parts”, Naval Research Logistics Quarterly, Vol. 17 No. 1, pp. 103-19.

Michaels, L. (1999), “The making of a lean aerospace supply chain”, Supply Chain Management: An International Journal, Vol. 4 No. 3, pp. 135-44.

Ministry of Defence (MoD) (UK) (2004), Promulgated by the Chiefs of Staff 2004, Joint Doctrine Publication 01: Joint Operations, Joint Doctrine and Concept Centre, Shrivenham.

Murphy, A.H. (1993), "What is a good forecast? An essay on the nature of goodness in weather forecasting", Weather and Forecasting, Vol. 8 No. 2, pp. 281-93.

Ord, K., Koehler, A. and Snyder, R. (2001), "Prediction intervals for ARIMA models", Journal of Business and Economic Statistics, Vol. 19 No. 2, pp. 217-25.

Pack, D. (1990), "In defense of ARIMA modelling", International Journal of Forecasting, Vol. 6 No. 2, pp. 211-18.

Pagels, C. (1969), "Exponential smoothing: some new variations”, Management Science, Vol. 12, pp. 311-15.

Palm, F.C. and Zellner, A. (1992), "To combine of not to combine? Issues of combining forecasts", International Journal of Forecasting, Vol. 11 No. 8, pp. 687-701.

Rafuse, M. (1995), "Reducing the need to forecast", International Journal of Logistics Management, Vol. 6 No. 2, pp. 103-8.

Regattieri, A., Gamberi, M., Gamberini, R. and Manzini, R. (2005), "Managing lumpy demand for aircraft spare parts", Journal of Air Transport Management, Vol. 11 No. 6, pp. 426-31.

Roman, S., Petrusha, R. and Kotary, N. (2002), Writing Excel Macros with VBA, O'Reilly, Cambridge, MA.

Sayed, H., Gabbar, H. and Miyazaki, S. (2009), "A hybrid statistical genetic-based demand forecasting expert system”, Expert Systems with Applications, Vol. 36 No. 9, pp. 11662-70.

Seymour, W. (2001), "In the flesh or online? Exploring qualitative research methodologies", Qualitative Research, Vol. 1 No. 2, pp. 147-68.

Silver, E., Pyke, D. and Peterson, R. (1998), Inventory Management and Production Planning and Scheduling, 3rd ed., John Wiley \& Sons, New York, NY.

Sniezek, J. (1989), “An examination of group process in judgmental forecasting”, International Journal of Forecasting, Vol. 5 No. 2, pp. 171-8.

Snyder, R. (2002), "Forecasting sales of slow and fast moving inventories", European Journal of Operational Research, Vol. 140 No. 3, pp. 684-99.

Syntetos, A. (2007), "A note on managing lumpy demand for aircraft spare parts", Journal of Air Transport Management, Vol. 13 No. 3, pp. 166-7.

Syntetos, A. and Boylan, J. (2001), "On the bias of intermittent demand estimates", International Journal of Production Economics, Vol. 71 Nos 1-3, pp. 457-66.

Syntetos, A. and Boylan, J. (2005), "The accuracy of intermittent demand estimates", International Journal of Forecasting, Vol. 21 No. 2, pp. 303-14.

Syntetos, A.A., Boylan, J.E. and Disney, S.M. (2009a), "Forecasting for inventory planning: a 50-review”, Journal of the Operational Research Society, Vol. 60 No. 1, pp. S149-S60.

Syntetos, A., Nikolopoulos, K., Boylan, J., Fildes, R. and Goodwin, P. (2009b), "The effects of integrating management judgement into intermittent demand forecasts", International Journal of Production Economics, Vol. 118 No. 1, pp. 72-81.
Forecasting in airforce supply chains 
IJLM

22,1

144

Teunter, R. and Sani, B. (2009), "On the bias of Croston's forecasting method”, European Journal of Operational Research, Vol. 194 No. 1, pp. 177-83.

Theil, H. (1966), Applied Economic Forecasting, Amsterdam-Holland Publishing Company, Amsterdam.

Tukey, J. (1962), “A quick, compact two-sample test to Duckworth's specifications", Technometrics, Vol. 1 No. 1, pp. 31-48.

Tysseland, B. (2009), "Spare parts optimization process and results: OPUS10 cases in the Norwegian defence", International Journal of Physical Distribution and Logistics Management, Vol. 39 No. 1, pp. 8-27.

Voss, C., Tsikriktsis, N. and Frohlich, M. (2002), "Case research in operations management", International Journal of Production and Operations Management, Vol. 22 No. 2, pp. 195-219.

Wallstrom, P. (2009), "Evaluation of forecasting techniques and forecast errors - with focus on intermittent demand", Licentiate Thesis, Lulea University of Technology, Lulea.

White, C. (1993), "Analyses of spares for new weapons systems using Markov chains”, European Journal of Operational Research, Vol. 66 No. 1, pp. 124-34.

Willemain, T., Smart, C. and Schwarz, H. (2004), "A new approach to forecasting intermittent demand for service parts inventories”, International Journal of Forecasting, Vol. 20 No. 3, pp. 375-87.

Willemain, T., Smart, C., Shockor, J. and DeSautels, P. (1994), "Forecasting intermittent demand in manufacturing: a comparative evaluation of Croston's method", International Journal of Forecasting, Vol. 10 No. 4, pp. 529-38.

Withington, T. (2008), "Maintenance on the fly", Defence Management Journal, Vol. 43, pp. 29-30.

Yin, R. (2003), Case Study Research: Design and Methods: 005, Applied Social Research Methods Series, 3rd ed., Sage, San Francisco, CA.

Zellner, A. (1986), "A tale of forecasting 1001 series: the Bayesian knight strikes again", International Journal of Forecasting, Vol. 2 No. 4, pp. 491-4.

Zinn, W. (1990), "Developing heuristics to estimate the impact of postponement on safety stock", The International Journal of Logistics Management, Vol. 1 No. 2, pp. 11-16.

\section{Corresponding author}

Matthew Downing can be contacted at: matthew.p.downing@boeing.com

To purchase reprints of this article please e-mail: reprints@emeraldinsight.com Or visit our web site for further details: www.emeraldinsight.com/reprints 